\title{
Prevalence and Associated Factors of Antenatal Depressive Symptoms in Pregnant Women Living in an Urban Area of Thailand
}

This article was published in the following Dove Press journal: International Journal of Women's Health

\author{
Pawanruj Tuksanawes' \\ Kasemsis Kaewkiattikun (iD) \\ Nitchawan Kerdcharoen ${ }^{2}$ \\ 'Department of Obstetrics \& \\ Gynecology, Faculty of Medicine Vajira \\ Hospital, Navamindradriraj University, \\ Bangkok, Thailand; ${ }^{2}$ Department of \\ Psychiatry, Faculty of Medicine Vajira \\ Hospital, Bangkok, Thailand
}

Background: Depression is a major public health problem in middle- and low-income countries. Depression in pregnancy has adverse effects on obstetric outcomes. Maternal depression remains under-recognized, under-diagnosed and undertreated in Thailand. Antenatal screening of depression is an important strategy to improve maternal and neonatal outcomes. This problem has rarely been investigated in Thailand, especially in urban areas. Objective: To discover the prevalence, associated factors, and predictive factors of depression in pregnant women living in an urban area.

Materials and Methods: This cross-sectional study of 402 pregnant women was conducted during antenatal care at the Department of Obstetrics and Gynecology, Faculty of Medicine Vajira Hospital, Navamindradhiraj University, Bangkok, Thailand, from 10 September to 31 November 2019. The participants were interviewed using a structured questionnaire that included a demographic profile, obstetric conditions, socio-cultural characteristics, and a Thai language version of the Center for Epidemiologic Studies-Depression Scale to assess depressive symptoms.

Results: Among a total 402 pregnant women, the prevalence of depressive symptoms in pregnant women in an urban area was $18.9 \%$. Depressive symptoms in pregnant women were significantly associated with divorce $(\mathrm{p}<0.001)$, low family income $(\mathrm{p}<0.03)$, financial insufficiency $(p<0.001)$, extended family $(p<0.001)$, history of previous abortion $(p=0.033)$, history of previous pregnancy complications $(p=0.044)$, current alcohol use ( $p$ $=0.03)$, current tobacco use $(\mathrm{p}=0.009)$, current substance abuse $(\mathrm{p}=0.002)$, marital conflict $(\mathrm{p}<0.001)$, and family conflict $(\mathrm{p}<0.001)$. The significant factors predicting depression in pregnant women were extended family (AOR 3.0, 95\% CI 1.59-5.51, $p=0.001$ ) and marital conflict (AOR 4.7, 95\% CI 2.37-9.11, $p<0.001$ ).

Conclusion: This study revealed that the prevalence of depressive symptoms in pregnant women living in an urban area in Thailand was $18.9 \%$. The significant associated factors of depressive symptoms were divorce, low family income, financial insufficiency, extended family, previous abortion, previous pregnancy complications, current alcohol use, current tobacco use, current substance abuse, marital conflict, and family conflict. Extended family and marital conflict were significant predictive factors for antenatal depressive symptoms.

Keywords: depression, depression in pregnancy, antenatal depression, CES-D, prevalence, risk factor, urban area, Thailand

\section{Introduction}

Depression is a common mental health problem leading to a variety of emotional and, physical problems, and decreased personal abilities. Depression is a leading
Correspondence: Kasemsis

Kaewkiattikun

Department of Obstetrics \& Gynecology,

10300 , Thailand

Tel +66882926988

Email kasem38@hotmail.com
International Journal of Women's Health 2020:12 849-858

849 
cause of disability around the world and contributes greatly to the global burden of disease. It is also the major contributor to suicide which numbers close to 800,000 cases per year. ${ }^{1}$ The World Health Organization (WHO) estimated the prevalence of depression in the world is 322 million. Nearly half of these people live in the South-Eastern Asia Region and Western Pacific Region. Depression increased by $18.4 \%$ between 2005 and 2015. The proportion of the global population with depression in 2015 was estimated to be $4.4 \%$. Globally, depressive disorders are ranked as the single largest contributor to non-fatal health loss $(7.5 \%$ of all Years Lived with Disability). ${ }^{2}$ In Thailand, the Thai national mental health survey 2007 reported that the prevalence of depression in Thai people was $2.2 \%{ }^{3}$

Many epidemiological studies have reported that women have an approximately 2 -fold greater prevalence, and higher level, of depression than men. ${ }^{2,45}$ In women, there are demonstrated that increased prevalence of depression fairly low in the early years of life, rising during adolescence and through reproductive age, decreasing in later years, and then disappear during the menopausal stage. ${ }^{6}$ The increasing prevalence of depression correlates with hormonal changes in women, particularly during puberty, prior to menstruation, following pregnancy and at perimenopause, suggests that female hormonal fluctuations may be a trigger for depression. ${ }^{6}$ Moreover, depression is more prevalent in pregnant than non-pregnant women. ${ }^{7}$ The increasing risk for the development of mood disorders and depression in pregnancy is explained by many dramatic changes during pregnancy, birth, and lactation such as hormone levels and brain-derived neurotrophic factor (BDNF) changes, ${ }^{7}$ cultural and societal changes, psychological changes, and the transition to motherhood. The pooled prevalence of antepartum depression in low- and middleincome countries was $25.3 \%$ (95\% CI 21.4-29.6\%) across 51 studies. ${ }^{8}$ Globally, antenatal depression prevalence varies widely from $15 \%$ to $65 \% .{ }^{9,10}$ Similarly, reports of antenatal depression prevalence in Thailand ranged from $12.51 \%$ to $46.8 \%{ }^{11,12}$ This wide range of prevalence depends on the study setting, population, cultural context, and screening instrument to detect depressive symptoms.

When comparing urban and rural areas, there is evidence that depression has a higher prevalence in urban areas than in rural areas. ${ }^{13}$ Urbanization affects mental health through the influence of increased socioeconomic stress, occupational pressure, overcrowding, polluted environment, high levels of violence, and reduced family and social support. ${ }^{14}$ Bangkok, for example, has high rates of inward and outward migration and markedly different healthcare delivery systems from rural areas; these factors have hindered a satisfactory increase in surveillance and healthcare system for mental health. ${ }^{15}$ Moreover, depression is more prevalent among urban women than men. Women are vulnerable and suffer from the burden of changes associated with urbanization. ${ }^{14}$ In addition, for pregnant women without a psychiatric history, the chance of antenatal depression is higher in urban rather than rural settings $(8.5 \%$ vs $3.4 \%){ }^{16}$

There is strong evidence that antenatal depression has adverse effects on obstetric outcomes such as fetal growth restriction, preterm delivery, and low birth weight. ${ }^{17,18}$ In addition, the baby whose mother has depression is at greater risk of emotional, behavioral and concentration problems during childhood and adolescence. ${ }^{19}$ Risk factors of antenatal depression are multifactorial including age, marital status, income, occupation, history of the previous mental disorder, antenatal follow-up, unplanned pregnancy, complication during to pregnancy, age of mother during pregnancy, conflict, and social support were associated with antenatal depression, ${ }^{20}$ number of gestations, unplanned pregnancy, history of fetal loss, ${ }^{21}$ birth preparedness, relationship with husband, social support, ${ }^{11}$ and not enough money. ${ }^{12}$

Although many previous studies have reported antenatal depression, little is known about antenatal depression in Thailand and in the South-East Asian region, despite a high prevalence of depression in this region. Furthermore, while most prior published papers reported studies conducted in rural or peri-urban areas, few studies have focused on urban areas, where more people in the developing world actually live. In addition, maternal depression remains under-recognized and undertreated in Thailand. This study, therefore, fills the gap in knowledge of antenatal depression in these settings. The aims of this study were to discover the prevalence and associated factors of depressive symptoms in pregnant women living in urban areas. Results of this study will contribute to provide valuable information for policymaking and service providing for antenatal depression screening and interventions in urban pregnant women to improve maternal and neonatal outcomes.

\section{Materials and Methods}

A cross-sectional study was conducted from 10 September to 31 November 2019 at the Department of Obstetrics and 
Gynecology, Faculty of Medicine Vajira Hospital, Navamindradhiraj University, Bangkok, Thailand. Approval for the study was obtained from the Research Ethics Board at Faculty of Medicine Vajira Hospital. Formal permission letters were secured from all respective local administrators. In addition, this study was conducted in accordance with the Declaration of Helsinki.

The studied population consisted of pregnant women living in Bangkok and attending antenatal care at the Department of Obstetrics \& Gynecology, Faculty of Medicine Vajira Hospital. Inclusion criteria were all pregnant Thai women over 20 years old who could read and communicate in Thai. Exclusion criteria were conditions that may affect emotional state or antenatal depression screening such as history of psychiatric illness, prior diagnosis of psychiatric disorders before pregnancy; conditions that may require emergency treatment at the time of interview such as having maternal complications (antepartum hemorrhage, eclampsia, umbilical cord prolapse), or fetal complications (fetal distress, non-reassuring fetal heart rate, premature rupture of membranes, preterm labor, intra-uterine growth retardation, fetal anomalies).

Sample size was calculated based on previous studies in a north-eastern province of Thailand; they found that the prevalence of antenatal depressive symptoms was $46.8 \% .^{12}$ The powers of $80 \%$ and a level of confidence of $95 \%$ were applied to determine the difference between groups. By adding $10 \%$ for incomplete data, a total 402 participants were included in this study by computerized simple random sampling technique.

All participants who fulfilled the inclusion and exclusion criteria were informed about study process in a private space at antenatal clinic by a well-trained research assistant, including its aim, interview procedures, benefits of the study, and potential hazards that may be caused to the participant physiologically and psychologically, and their right to leave the study at any time they desired or feel uncomfortable about anything in the study. Data from the study always remained confidential. The research assistant would provide all participants sufficient time to decide whether to participate independently and voluntarily. The non-participants would not affect the quality of care they received. After understanding all processes, those who would be participating in the study provided written informed consent to the research assistant.

The eligible participants were interviewed and administrated verbally by a well-trained research assistant, using a structured questionnaire which included demographic data (age, marital status, educational status, occupation, family income, family type, habitation, underlying disease, husband's education status and occupation); obstetrics data (gravida, gestational age, previous abortion, previous pregnancy complications, and current pregnancy complication); and socio-cultural data (alcohol use, tobacco use, substance abuse, marital conflict, and family conflict). Depression symptoms were assessed by using a Thai language version of the Center for Epidemiologic StudiesDepression Scale (CES-D).

In this study, marital conflict was assessed by asking questions of the state of tension, stress, and disagreements with their husbands about topics such as household tasks and maintenance, warmth and affect in their relationship, major financial decisions, time for self, time with family, and fair sharing of workload between partners. Family conflict was assessed by asking questions of overt disagreement between the participant and any family members such as physical and verbal aggression, openly fighting, blaming, expressed anger, arguing, negative tone, and unresolved conflicts. Nuclear family was defined as a family consisting of two parents and their children. Extended family was defined as a family consisting of two parents, their children, and their relatives such as aunts, uncles, grandparents, and cousins, all living in the same household. Gestational age was divided into trimesters: the first trimester is from week 1 to the end of week 12 . The second trimester is from week 13 to the end of week 26. The third trimester is from week 27 to the end of the pregnancy.

The depression screening tool used in this study was the CES-D because it contained all of the common symptoms of major depression, including depressive mood, feelings of guilt and worthlessness, psychomotor retardation, loss of appetite, and sleep disturbance. ${ }^{22}$ It is relatively more congruent with current diagnostic criteria for depression which offers a valid item set without biases related to social concerns or sex. ${ }^{23}$ Moreover, it is easy to use, takes little time, has acceptable sensitivity, specificity, accuracy, and high internal consistency reliability (Cronbach's $\alpha=0.85-0.94)$ for measuring depressive symptoms in antenatal clinics. ${ }^{23,24}$ The CES-D was originally developed by Radloff in $1997 .^{22}$ It is one of the most frequently used screening tools for depression. The CES-D is a short self-report of 20-items questionnaire to assess the frequency of depressive symptoms during the past week on a 0-3 Likert-type scale ("rarely or none of the 
time" to "most or all of the time"), and total scores range from 0 to 60 . The CES-D has been translated into Thai language for a Thai cultural context. It was performed among 69 medical personnel and 30 psychiatric patients. The Thai CES-D (T-CES-D) scores $\geq 19$ suggest the presence of a possible depression with $93.33 \%$ sensitivity, $94.2 \%$ specificity, and 0.92 reliability. $^{25}$ If the participant had a positive screening test, the authors would further consult with a psychiatrist for proper diagnostic assessment and initiation of treatment.

The primary outcome of this study was the prevalence of depressive symptoms in pregnant women living in an urban area by using T-CES-D scores $\geq 19$. The secondary outcome was the risk factors associated with depressive symptoms in urban pregnant women. The data were analyzed by statistician using SPSS version 22 (IBM Corp., Armonk, NY, USA). ${ }^{26}$ Chi-square test was used for categorical data analysis. Univariate and multivariate analysis were further entered into logistic regression analysis to determine independent predictors of depression in pregnant women and presented as an odds ratio and 95\% confidence interval (CI). A p-value of less than 0.05 was considered statistically significant.

\section{Results}

Four hundred and ten pregnant women who fulfilled the inclusion and exclusion criteria were approached, 8 refused to participate in the study. A total 402 pregnant women were finally complete results and eligible for analysis. Table 1 shows baseline characteristics of all 402 pregnant women. Socio-demographic characteristics revealed the majority were 25-29 years old (29.6\%), were married (78.9\%), had a high school education $(40.5 \%)$, were company employees $(49.3 \%)$, had monthly family income $\leq 20,000$ baht $(52.0 \%)$, had financial insufficiency $(69.7 \%)$, were from nuclear families $(71.4 \%)$, lived in a detached house (36.1\%), and had no underlying disease $(91.8 \%)$. Most of their husbands had a high school education $(45.3 \%)$ and were company employees $(63.9 \%)$. The obstetric characteristics showed that the majority were multipara $(70.9 \%)$, in their third trimester $(52.5 \%)$, had no previous abortion (77.6\%), had no pregnancy complications $(59.0 \%)$, and no current pregnancy complications $(81.3 \%)$. The socio-cultural characteristics showed that most of the participants had no alcohol use (81.6\%), no tobacco use (91.5\%), no substance abuse (98.3\%), no marital conflict (76.1\%), and no family conflict $(88.1 \%)$. There were $76(18.9 \%)$ pregnant women had antenatal depressive symptoms according to CES-D screening; therefore, the prevalence of antenatal depressive symptoms was $18.9 \%$.

The association between baseline characteristics with antenatal depressive symptoms is shown in Table 1. Antenatal depressive symptoms were significantly associated with divorced $(\mathrm{p}<0.001)$, low income $(\mathrm{p}=0.030)$, financial insufficiency ( $p<0.001)$, extended family ( $p<0.001)$, previous abortions $(\mathrm{p}=0.033)$, previous pregnancy complications $(p=0.044)$, current alcohol use $(p=0.03)$, current tobacco use $(p=0.009)$, substance abuse $(p=0.002)$, marital conflict ( $\mathrm{p}<0.001)$, and family conflict $(\mathrm{p}<0.001)$.

To analyze factors predicting antenatal depression, univariable logistic regression analysis found that marital status, income, financial insufficiency, family type, previous abortion, previous pregnancy complications, alcohol use, tobacco use, substance abuse, marital conflict, and family conflict were significant factors $(p<0.05)$. Only variables that were statistically significant in the univariable analysis were retained for inclusion in the multivariable analysis. After adjusting OR estimated by multiple logistic regression adjusting for marital status, income, insufficient income, family type, previous abortion, previous pregnancy complications, alcohol use, tobacco use, substance abuse, marital conflict, and family conflict were analyzed. This study revealed that the significant factors predicting antenatal depression were extended family $(\mathrm{AOR}=3.0,95 \% \mathrm{CI} 1.59-5.51, p=0.001)$ and marital conflict $(\mathrm{AOR}=4.7,95 \%$ CI 2.37-9.11, $p<0.001)$ are presented (see Table 2).

\section{Discussion}

This cross-sectional study has identified prevalence and predicting factors associated with depressive symptoms in pregnancy. Results demonstrated that prevalence rate of depressive symptoms in pregnant women was $18.9 \%$. This finding is consistent with the result of global estimates and many studies in Asian pregnant women. The WHO global estimation for depression in pregnant women was $15.6 \%{ }^{27}$ Studies conducted in Asian countries across 86 studies reported that the overall Asian prevalence of perinatal depression was about $20 \%{ }^{28}$ It was $13.3-16.7 \%$ in Japan, $18.9-22.1 \%$ in Hong Kong, $12-12.9 \%$ in Taiwan, $20 \%$ in Singapore, $20 \%$ in Southern Asia, ${ }^{28}$ and $12.51 \%$ in Thailand. $^{11}$

In terms of country income, a recent systematic review and meta-analysis revealed that antenatal depression prevalence is higher in low-income countries (pool 
Table I Demographic Characteristics of Pregnant Women and Association with Depressive Symptoms

\begin{tabular}{|c|c|c|c|c|c|c|c|}
\hline \multirow[t]{4}{*}{ Characteristics } & \multirow{3}{*}{\multicolumn{2}{|c|}{ Total $(n=402)$}} & \multicolumn{4}{|c|}{ Antenatal Depression } & \multirow[t]{4}{*}{ p-value } \\
\hline & & & \multicolumn{2}{|c|}{ Depression } & \multicolumn{2}{|c|}{ No Depression } & \\
\hline & & & \multicolumn{2}{|c|}{ (CES-D Score $\geq 19$ ) } & \multicolumn{2}{|c|}{ (CES-D Score < I9) } & \\
\hline & $\mathbf{n}$ & $\%$ & $\mathbf{n}$ & $\%$ & $\mathbf{n}$ & $\%$ & \\
\hline Total & 402 & 100 & 76 & 18.9 & 326 & 81.1 & \\
\hline \multicolumn{8}{|l|}{ Age (years) } \\
\hline $20-24$ & 83 & 20.6 & 16 & 19.3 & 67 & 80.7 & 0.997 \\
\hline $25-29$ & 119 & 29.6 & 22 & 18.5 & 97 & 81.5 & \\
\hline $30-34$ & 106 & 26.4 & 21 & 19.8 & 85 & 80.2 & \\
\hline $35-39$ & 70 & 17.4 & 13 & 18.6 & 57 & 81.4 & \\
\hline$\geq 40$ & 24 & 6 & 4 & 16.7 & 20 & 83.3 & \\
\hline \multicolumn{8}{|l|}{ Marital Status } \\
\hline Unmarried & 69 & 17.2 & 16 & 23.2 & 53 & 76.8 & $<0.001$ \\
\hline Married & 317 & 78.9 & 51 & 16.1 & 266 & 83.9 & \\
\hline Divorced & 16 & 4 & 9 & 56.3 & 7 & 43.8 & \\
\hline \multicolumn{8}{|l|}{ Educational Status } \\
\hline Elementary school & 25 & 6.2 & 5 & 20 & 20 & 80 & 0.286 \\
\hline High school & 163 & 40.5 & 38 & 23.3 & 125 & 76.7 & \\
\hline Diploma's degree & 64 & 15.9 & 10 & 15.6 & 54 & 84.4 & \\
\hline Bachelor's degree & 150 & 37.3 & 23 & 15.3 & 127 & 84.7 & \\
\hline \multicolumn{8}{|l|}{ Occupation } \\
\hline Student & 15 & 3.7 & 3 & 20 & 12 & 80 & 0.429 \\
\hline Company Employee & 198 & 49.3 & 35 & 17.7 & 163 & 82.3 & \\
\hline housekeeper & 57 & 14.2 & 15 & 26.3 & 42 & 73.7 & \\
\hline Government employee & 33 & 8.2 & 3 & 9.1 & 30 & 90.9 & \\
\hline Business owner & 56 & 13.9 & 10 & 17.9 & 46 & 82.1 & \\
\hline Unemployed & 43 & 10.7 & 10 & 23.3 & 33 & 76.7 & \\
\hline \multicolumn{8}{|l|}{ Family income (THB) } \\
\hline$\leq 20,000$ & 209 & 52.0 & 48 & 23.0 & 161 & 77.0 & 0.030 \\
\hline$>20,000$ & 193 & 48.0 & 28 & 14.5 & 165 & 85.5 & \\
\hline \multicolumn{8}{|l|}{ Financial insufficiency } \\
\hline No & 122 & 30.3 & 83 & 68 & 39 & 32 & $<0.001$ \\
\hline Yes & 280 & 69.7 & 243 & 86.8 & 37 & 13.2 & \\
\hline \multicolumn{8}{|l|}{ Type of family } \\
\hline Nuclear family & 287 & 71.4 & 40 & 13.9 & 247 & 86.1 & $<0.001$ \\
\hline Extended family & 115 & 28.6 & 36 & 31.3 & 79 & 68.7 & \\
\hline \multicolumn{8}{|l|}{ Habitation } \\
\hline Detached House & 145 & 36.1 & 27 & 18.6 & 118 & 81.4 & 0.459 \\
\hline Apartment/Flat & 116 & 28.9 & 26 & 22.4 & 90 & 77.6 & \\
\hline Townhouse & 118 & 35.1 & 23 & 16.3 & 118 & 83.7 & \\
\hline \multicolumn{8}{|l|}{ Underlying disease } \\
\hline No & 369 & 91.8 & 71 & 19.2 & 298 & 80.8 & 0.565 \\
\hline Yes & 33 & 8.2 & 5 & 15.2 & 28 & 84.8 & \\
\hline \multicolumn{8}{|l|}{ Husband's Educational Status } \\
\hline Elementary school & 42 & 10.4 & 7 & 16.7 & 35 & 83.3 & 0.074 \\
\hline High school & 182 & 45.3 & 43 & 23.6 & 139 & 76.4 & \\
\hline Diploma's degree & 71 & 17.7 & 14 & 19.7 & 57 & 80.3 & \\
\hline Bachelor's degree & 107 & 26.6 & 12 & 11.2 & 95 & 88.8 & \\
\hline
\end{tabular}

(Continued) 
Table I (Continued).

\begin{tabular}{|c|c|c|c|c|c|c|c|}
\hline \multirow[t]{4}{*}{ Characteristics } & \multirow{3}{*}{\multicolumn{2}{|c|}{ Total $(n=402)$}} & \multicolumn{4}{|c|}{ Antenatal Depression } & \multirow[t]{4}{*}{ p-value } \\
\hline & & & \multicolumn{2}{|c|}{ Depression } & \multicolumn{2}{|c|}{ No Depression } & \\
\hline & & & \multicolumn{2}{|c|}{$($ CES-D Score $\geq 19$ ) } & \multicolumn{2}{|c|}{ (CES-D Score < 19) } & \\
\hline & $\mathbf{n}$ & $\%$ & $\mathbf{n}$ & $\%$ & $\mathbf{n}$ & $\%$ & \\
\hline \multicolumn{8}{|l|}{ Husband's Occupation } \\
\hline Company Employee & 257 & 63.9 & 46 & 17.9 & 211 & 82.1 & 0.137 \\
\hline Business owner & 71 & 17.7 & 12 & 16.9 & 59 & 83.1 & \\
\hline Government employee & 63 & 15.7 & 13 & 20.6 & 50 & 79.4 & \\
\hline Unemployed & 11 & 2.7 & 5 & 45.5 & 6 & 54.5 & \\
\hline \multicolumn{8}{|l|}{ Gravida } \\
\hline Primiparity & 117 & 29.1 & 17 & 14.5 & 100 & 85.5 & 0.142 \\
\hline Multiparity & 285 & 70.9 & 59 & 20.7 & 226 & 79.3 & \\
\hline \multicolumn{8}{|l|}{ Gestational Age } \\
\hline First Trimester & 59 & 14.7 & 8 & 13.6 & 51 & 86.4 & 0.497 \\
\hline Second Trimester & 132 & 32.8 & 25 & 18.9 & 107 & 81.1 & \\
\hline Third Trimester & 211 & 52.5 & 43 & 20.4 & 168 & 79.6 & \\
\hline \multicolumn{8}{|l|}{ Previous Abortion } \\
\hline No & 312 & 77.6 & 52 & 16.7 & 260 & 83.3 & 0.033 \\
\hline Yes & 90 & 22.4 & 24 & 26.7 & 66 & 73.3 & \\
\hline \multicolumn{8}{|c|}{ Previous pregnancy Complications } \\
\hline No & 237 & 59.0 & 44 & 18.6 & 193 & 81.4 & 0.044 \\
\hline Yes & 48 & 11.9 & 15 & 31.3 & 33 & 68.8 & \\
\hline \multicolumn{8}{|c|}{ Current pregnancy complications } \\
\hline No & 326 & 81.3 & 56 & 17.2 & 270 & 82.8 & 0.067 \\
\hline Yes & 76 & 18.9 & 20 & 26.3 & 56 & 73.7 & \\
\hline \multicolumn{8}{|l|}{ Alcohol Use } \\
\hline No & 328 & 81.6 & 57 & 17.4 & 271 & 83.1 & 0.03 \\
\hline Current use & 13 & 3.2 & 6 & 46.2 & 7 & 53.8 & \\
\hline Previous use & 61 & 15.2 & 13 & 21.3 & 48 & 78.7 & \\
\hline \multicolumn{8}{|l|}{ Tobacco Use } \\
\hline No & 368 & 91.5 & 63 & 17.1 & 305 & 82.9 & 0.009 \\
\hline Current use & 4 & 1 & 2 & 50 & 2 & 50 & \\
\hline Previous use & 30 & 7.5 & 11 & 36.7 & 19 & 63.3 & \\
\hline \multicolumn{8}{|l|}{ Substance abuse } \\
\hline No & 395 & 98.3 & 71 & 18 & 324 & 82 & 0.002 \\
\hline Current use & 4 & 1 & 3 & 75 & 1 & 25 & \\
\hline Previous use & 3 & 0.7 & 2 & 66.7 & 1 & 33.3 & \\
\hline \multicolumn{8}{|l|}{ Marital conflict } \\
\hline No & 306 & 76.1 & 34 & 11.1 & 272 & 88.9 & $<0.001$ \\
\hline Yes & 98 & 23.9 & 42 & 43.8 & 54 & 56.3 & \\
\hline \multicolumn{8}{|l|}{ Family conflict } \\
\hline No & 354 & 88.1 & 53 & 15 & 301 & 85 & $<0.001$ \\
\hline Yes & 48 & 11.9 & 23 & 47.9 & 25 & 52.1 & \\
\hline
\end{tabular}

Note: Data are presented as number (\%).

Abbreviation: THB, Thai baht. 
Table 2 Univariate and Multiple Logistic Regression Analyses of Factors Associated with Depression in Pregnant Women

\begin{tabular}{|c|c|c|c|c|c|c|}
\hline \multirow[t]{2}{*}{ Factors } & \multicolumn{3}{|c|}{ Univariate Analysis } & \multicolumn{3}{|c|}{ Multivariate Analysis } \\
\hline & $\mathbf{O R}^{\mathbf{a}}$ & $95 \% \mathrm{Cl}$ & $p$-value & $\mathbf{A O R}^{\mathbf{b}}$ & $95 \% \mathrm{Cl}$ & $p$-value \\
\hline \multicolumn{7}{|l|}{ Marital Status } \\
\hline Unmarried & 1.0 & Reference & & 1.0 & Reference & \\
\hline Married & 1.6 & $(0.84-2.97)$ & 0.161 & 1.1 & $(0.5 I-2.56)$ & 0.755 \\
\hline Divorced & 6.7 & $(2.39-18.82)$ & $<0.001$ & 2.3 & $(0.57-9.59)$ & 0.237 \\
\hline \multicolumn{7}{|c|}{ Family income (THB) } \\
\hline$\leq 20,000$ & 1.0 & Reference & & 1.0 & Reference & \\
\hline$>20,000$ & 1.8 & $(1.05-2.94)$ & 0.032 & 1.2 & $(0.60-2.42)$ & 0.594 \\
\hline \multicolumn{7}{|c|}{ Financial insufficiency } \\
\hline No & 1.00 & Reference & & 1.0 & Reference & \\
\hline Yes & 3.09 & $(1.85-5.16)$ & $<0.001$ & 1.7 & $(0.87-3.38)$ & 0.117 \\
\hline \multicolumn{7}{|l|}{ Type of family } \\
\hline Nuclear family & 1.0 & Reference & & 1.0 & Reference & \\
\hline Extended family & 2.8 & $(1.68-4.72)$ & $<0.001$ & 3.0 & $(1.59-5.5 I)$ & 0.001 \\
\hline \multicolumn{7}{|l|}{ Previous Abortion } \\
\hline No & 1.0 & Reference & & 1.0 & Reference & \\
\hline Yes & 1.8 & $(1.05-3.16)$ & 0.034 & 1.9 & $(0.98-3.86)$ & 0.059 \\
\hline \multicolumn{7}{|c|}{ Previous pregnancy Complications } \\
\hline No & 1.0 & Reference & & 1.0 & Reference & \\
\hline Yes & 2.2 & $(1.04-4.80)$ & 0.040 & 2.2 & $(0.83-5.76)$ & 0.114 \\
\hline \multicolumn{7}{|l|}{ Alcohol use } \\
\hline No & 1.0 & Reference & & 1.0 & Reference & \\
\hline Currently use & 4.1 & $(1.32-12.58)$ & 0.015 & 1.6 & $(0.33-7.95)$ & 0.561 \\
\hline Previous use & 1.3 & $(0.66-2.53)$ & 0.464 & 0.7 & $(0.25-1.91)$ & $0.48 \mathrm{I}$ \\
\hline \multicolumn{7}{|l|}{ Tobacco use } \\
\hline No & 1.0 & Reference & & 1.0 & Reference & \\
\hline Currently use & 4.8 & $(0.67-35.02)$ & 0.118 & 0.7 & $(0.07-8.0 \mathrm{I})$ & 0.797 \\
\hline Previous use & 2.8 & $(1.27-6.18)$ & 0.011 & 1.5 & $(0.45-5.19)$ & 0.498 \\
\hline \multicolumn{7}{|l|}{ Substance abuse } \\
\hline No & 1.0 & Reference & & 1.0 & Reference & \\
\hline Currently use & 13.7 & $(1.40-133.54)$ & 0.024 & 8.6 & $(0.55-134.24)$ & 0.124 \\
\hline Previous use & 9.1 & $(0.82-102.04)$ & 0.073 & 2.6 & $(0.16-41.59)$ & 0.503 \\
\hline \multicolumn{7}{|l|}{ Marital conflict } \\
\hline No & 1.0 & Reference & & 1.0 & Reference & \\
\hline Yes & 6.2 & $(3.63-10.66)$ & $<0.001$ & 4.7 & $(2.37-9.11)$ & $<0.001$ \\
\hline \multicolumn{7}{|l|}{ Family conflict } \\
\hline No & 1.0 & Reference & & 1.0 & Reference & \\
\hline Yes & 5.2 & $(2.76-9.88)$ & $<0.001$ & 2.1 & $(0.95-4.74)$ & 0.068 \\
\hline
\end{tabular}

Notes: ${ }^{\mathrm{a} C r u d e} \mathrm{OR}$ estimated by binary logistic regression. ${ }^{\mathrm{b}} \mathrm{AOR}$ estimated by multiple logistic regression.

Abbreviations: THB, Thai baht; OR, odds ratio; $\mathrm{AOR}$, adjusted odds ratio; $\mathrm{Cl}$, confidence interval.

prevalence $34.0 \%, 95 \%$ CI 33.1-34.9) than middle-income countries (pool prevalence $22.7 \%$, 95\% CI 20.1-25.2). ${ }^{11}$ The prevalence of this study is consistent with many other middle-income countries, such as $22 \%$ in South Africa, ${ }^{29}$
$13.4 \%$ in Sudan, ${ }^{30}$ and $14.8 \%$ in Brazil. ${ }^{31}$ The higher prevalence in low-income countries could be explained by risk factors associated with mental health disorders are more common, such as economic difficulty, inequality, 
poor health care, low education, and rapid population growth. Nevertheless, some prior reports from middleincome countries showed as high a prevalence as in lowincome countries; for example, $35.7 \%$ in India, ${ }^{32} 40.8 \%$ in Pakistan, ${ }^{33} 28.4 \%$ in China, ${ }^{34}$ and $27.5 \%$ in Turkey. ${ }^{21}$ On the other hand, some reports from low-income countries showed low prevalence; for example, $10.7 \%$ in Malawi ${ }^{35}$ and $15.2-24.2 \%$ in Ethiopia, ${ }^{36-38}$ This discrepancy in prevalence between countries may be due to the differences in study methodology, study setting, depression screening tool, culture, socio-economic and socio-demographic variation between regions.

In this study, significant associations were seen between divorce, low income, financial insufficiency, extended family, previous abortion, previous pregnancy complications, alcohol use, tobacco use, substance abuse, marital conflict, and family conflict and antenatal depression. Similar findings have been reported in previous systematic reviews and meta-analyses from Ethiopia ${ }^{37}$ and Africa. ${ }^{39}$ They found that pregnant women who had unfavorable marital conditions, economic difficulties, bad obstetric history, previous history of abortion, previous history of pregnancy complications, marital conflict, lack of social support from husband, and poor support from relatives were at higher risk of antenatal depression. All these factors could be stressful situations or stimulating events that affect mental health. Thus, antenatal depression screening in pregnant women with these factors will increase the chance of early diagnosis and proper management of depression during pregnancy to prevent negative obstetric outcomes.

After adjusting for confounding effects using multiple logistic regression analysis to adjust for significant associated factors, this study found that the significant predictive factors for antenatal depression were extended family and marital conflict. Pregnant women with antenatal depressive symptoms had 3 times more extended family than nuclear family. This finding is different from previous reports from Turkey, ${ }^{40-42}$ where they found that there was no significant difference in antenatal depression between extended and nuclear family settings. The possible explanation for our findings in this study may be due to family culture in Thailand. When women get married, they will typically move to live with their husband and his family in the same house. They must adapt to their husband's family culture and be responsible for household work, leading to emotional stress. ${ }^{43}$ Having conflict with the parents-in-law has been associated antenatal depression. ${ }^{28}$ Support from family members is an important buffer against depression in pregnant women. ${ }^{40,43}$ The low levels of emotional support from spouse, mother-in-law, and family members in extended families correlates more strongly with antenatal depression in extended rather than nuclear family settings. $^{40,42}$ Moreover, limited family support will increase risk for postpartum depression. ${ }^{44}$ Therefore, healthcare providers should encourage family relationships and support, particularly in pregnant women with extended family.

Another significant predictive factor for antenatal depressive symptoms in this study was marital conflict, which was at a rate more than 5 times than among those with good spousal relationships. This finding is consistent with earlier reports from South Africa and Ethiopia. They found that a significant predictive factors for depression in pregnant women was physical violence from the partner. ${ }^{36,38}$ Moreover, this finding was also confirmed by a systematic review and meta-analysis, in which pregnant women with marital conflict were 7 times more likely to develop antenatal depression. ${ }^{37}$ In contrast, a lack of these expected supports from the partner could have impact on depressive symptoms. ${ }^{28}$ Pregnant women who lacked spousal support were 3 times more likely to have antenatal depression. ${ }^{37}$ Marital conflict may come from poor intimacy with partners, feeling insecure about bodily changes, sexually unattractiveness, and need extra support from their partners. $^{28}$ Therefore, healthcare providers should seek to uncover marital conflict and spousal support during antenatal care, counseling them about the effects on pregnancy, and provide counseling to mitigate the conflict.

The results of this study have implications for institutes to implement antenatal depression screening programs with adequate population coverage. Moreover, health professionals should provide psychiatric counseling to all pregnant women and their families during the antenatal period, especially those who are at risk of depression. Encouraging support from spouse and family is essential to diminish and prevent antenatal depression. This approach may be generalizable to postpartum women to prevent maternal and neonatal morbidities.

The strengths of this study were large sample size, the CES-D questionnaire had high sensitivity and specificity that was validated for used in Thai people and participants were interviewed by a well-trained research assistant. However, this study had many limitations: it was a cross-sectional study hence the relationship 
between variables could not be proven. The answers were self-reported with no means of verification, and thus subject to bias. Moreover, participants were interviewed during current pregnancies, not completed pregnancies; they may have had some problems associated with depression after being interviewed. Another limitation of this study includes factors that might have affected the interviewees, such as answering questions about drug use that is illegal in Thailand. It may have resulted in a reluctance to disclose such drug use truthfully. Another limitation of this study includes factors that might affect depression in pregnant women such as attitudes and beliefs about pregnancy, pregnancy plan, and worries about appearance that were not evaluated. Further research would compare depression in pregnant women in urban and rural settings, compare antepartum and postpartum depression, and compare adult and adolescent pregnancy. Other research would study large populations or in multicenter hospitals in urban areas.

\section{Conclusion}

Prevalence of depression in pregnant women in an urban area of Thailand was $18.9 \%$ according to the CES-D screening. Those pregnant women who were more likely to have depression included those who were divorced, had low family income, financial insufficiency, extended family, previous abortion, previous pregnancy complications, current alcohol use, current tobacco use, current substance abuse, marital conflict, and family conflict. Predictive factors for depression in pregnant women were extended family and marital conflict. Therefore, screening of depression in pregnant women is an essential component of antenatal care service.

\section{Acknowledgment}

The authors would like to thank all participants in this study and all staff in the data collection team. The authors would likely to express gratitude to Mr. Jason Cullen for proofreading the earlier drafts of the manuscript. Lastly, this study was made possible through funding and support from Navamindradhiraj University. The funders had no role in the study design, data collection and analysis, decision to publish, or preparation of the manuscript.

\section{Disclosure}

The authors report no conflicts of interest in this research.

\section{References}

1. Murray CJL, Lopez AD, editors. The Global Burden of Disease and Injury Series, Volume1: A Comprehensive Assessment of Mortality and Disability from Disease, Injuries, and Risk Factors in 1990 and Projected to 2020. Cambridge, MA: Published by the Harvard School of Public Health on behalf of the World Health Organization and the World Health Organization and the World Bank, Harvard University; 1996.

2. World Health Organization. Depression and Other Common Mental Disorders: Global Health Estimates. Geneva: World Health Organization; 2017.

3. Kittirattanapaiboon P, Tantirangsee N, Chutha W, et al. Thai Mental Health Survey Working Group. Prevalence of Mental Disorders and Mental Health Problems: Thai National Mental Health Survey 2013. Published by Bureau of Mental Health Service Administration, Department of Mental Health; 2013.

4. Van de Velde S, Bracke P, Levecque K. Gender differences in depression in 23 European countries. Cross-national variation in the gender gap in depression. Soc Sci Med. 2010;71:305-313.

5. Kessler RC, Bromet EJ. The epidemiology of depression across cultures. Annu Rev Public Health. 2013;34:119-138.

6. Albert PR. Why is depression more prevalent in women? J Psychiatry Neurosci. 2015;40(4):219-220.

7. Lommatzsch M, Hornych K, Zingler C, Schuff-Werner P, Hoppner J, Virchow JC. Maternal serum concentrations of BDNF and depression in the perinatal period. Psychoneuroendocrinology. 2006;31 (3):388-394.

8. Gelaye B, Rondon M, Araya R, Williams MA. Epidemiology of maternal depression, risk factors, and child outcomes in low-income and middle-income countries. Lancet Psychiatry. 2016;3(10): 973-982.

9. Fekadu Dadi A, Miller ER, Bisetegen TA, Mwanri L. Global Burden of Antenatal Depression and its Association with Adverse Birth Outcomes: an Umbrella Review. BMC Public Health. 2020;20 (173):1-16.

10. Fekadu Dadi A, Miller ER, Mwanri L, Alebel A. Antenatal depression and its association with adverse birth outcomes in low and middle-income countries: A systematic review and meta-analysis. PLoS One. 2020;15(1):e0227323. doi:10.1371/journal.pone.0227323

11. Rodpipat S Relationships between age, perceived pregnancy risks, perceived marital competence, marital relationship, social support, and antepartum depression. Master's Thesis, Faculty of Nursing, Chulalongkorn University; 2004.

12. Phoosuwan N, Eriksson L, Lundberg PC. Antenatal depressive symptoms during late pregnancy among women in a north-eastern province of Thailand: prevalence and associated factors. Asian J Psychiatr. 2018;36:102-107. doi:10.1016/j.ajp.2018.06.012

13. Probst JC, Laditka SB, Moore CG, Harun N, Powell MP, Baxley EG. Rural-Urban Differences in Depression Prevalence: implications for Family Medicine. Fam Med. 2006;38(9):653-660.

14. Srivastava K. Urbanization and Mental Health. Ind Psychiatry J. 2009;18(2):75-76.

15. Kongsuk T, Supanya S, Kenbubpha K, Phimtra S, Sukhawaha S, Leejongpermpoon J. Services for depression and suicide in Thailand. WHO-SEAJPH. 2017;6(1):34-38.

16. Bilszta JLC, Gu YZ, Meyer D, Buist AE. A geographic comparison of the prevalence and risk factors for postnatal depression in an Australian population. Aust N Z Public Health. 2008;32:424-430.

17. Grote NK, Bridge JA, Gavin AR, Melville JL, Lyengar S, Katon WJA. Meta-analysis of Depression During Pregnancy and the Risk of Preterm Birth, Low Birth Weight, and Intrauterine Growth Restriction. Arch Gen Psychiatry. 2010;67(10):1012-1024.

18. Szegda K, Markenson G, Bertone-Johnson ER, Chasan-Taber L. Depression during pregnancy: a risk factor for adverse neonatal outcomes? A critical review of the literature. J Matern Fetal Neonatal Med. 2014;27(9):960-967. 
19. Field T. Prenatal depression effects on early development: a review. Infant Behave Dev. 2011;34:1-14.

20. Getinet W, Amare T, Boru B, Shumet S, Worku W, Azale T. Prevalence and Risk Factors for Antenatal Depression in Ethiopia: systematic Review. Depress Res Treat. 2018;2018:3649269. doi:10.1155/2018/3649269

21. Golbasi Z, Kelleci M, Kisacik G, Cetin A. Prevalence and correlated of depression in pregnancy among Turkish women. Matern Child Health J. 2010;14(4):485-491.

22. Radloff LS, The CES-D. scale: a self-report depression scale for research in the general population. Appl Psychol Meas. 1997;1 (3):385-401.

23. Carleton RN, Thibodeau MA, Teale MJN, et al. The Center for Epidemiologic Studies Depression Scale: A Review with a Theoretical and Empirical Examination of Item Content and Factor Structure. PLoS One. 2013;8(3):e58067. doi:10.1371/journal. pone. 0058067

24. Chorwe-Sungani G, Chipps J. A systematic review of screening instruments for depression for use in antenatal services in low resource settings. BMC Psychiatry. 2017;17(112):1-10.

25. Kuptniratsaikul V, Pekuman P. The Study of the Center for Epidemiologic Studies-Depression Scale (CES-D) in Thai people. Siriiaj Hosp Gaz. 1997;49:442-448.

26. IBM Corp. IBM SPSS Statistics for Windows, Version 22.0. Armonk, NY: IBM Corp; 2013.

27. World Health Organization, Maternal mental health, 2018, https:// www.who.int/mental_health/maternal-child/maternal_mental_health/ en/.

28. Roomruangwong C, Epperson CN. Perinatal depression in Asian women: prevalence, associated factors, and cultural aspects. Asian Biomed. 2011;5(2):179-193.

29. van Heyningen T, Myer L, Onah M, Tomlinson M, Field S, Antenatal Depression HS. Adversity in Urban South Africa. Affect Disord. 2016;203:121-129.

30. Handady SO, Sakin HH, Ahmed KYM, Alawad AAM. Prevalence of antenatal depression among pregnant women in Khartoum maternity hospital in Sudan. Am J Psychol Behav Sci. 2015;2(4):141-145.

31. Silva MMJ, Leite EPRC, Nogueira DA, Clapis MJ. Depression in pregnancy. Prevalence and associated factors. Invest Educ Enferm. 2016;34(2):342-350.

32. Sheeba B, Nath A, Metgud CS, Krishna M, Venkatesh S, Vindhya $\mathrm{J}$ and Murthy GVS. Prenatal Depression and. Its Associated Risk Factors Among Pregnant Women in Bangalore: A Hospital Based Prevalence Study. Front Public Health. 2019;7:108.
33. Sabir M, Nagi MLF, Kazmi TH. Prevalence of antenatal depression among women receiving antenatal care during last trimester of pregnancy in a tertiary care private institute of Lahore. Pak J Med Sci. 2019;35(2):527-531.

34. Zhang L, Yang X, Zhao J, Zhang W, Cui C, Yang F. Ma R and Jia Y. Prevalence of Prenatal Depression Among Pregnant Women and the Importance of Resilience: A Multi-Site Questionnaire-Based Survey in Mainland China. Front Psychiatry. 2020;11:374.

35. Stewart RC, Umar E, Tomenson B, Creed F. A cross-sectional study of antenatal depression and associated factors in Malawi. Archives of Women's Mental Health. 2014;17(2):145.

36. Habtamu Belete A, Alemayehu Assega M, Alemu Abajobir A, Abebe Belay Y, Kassahun Tariku M. Prevalence of antenatal depression and associated factors among pregnant women in Aneded woreda, North West Ethiopia: A community based cross-sectional study. BMC Res Notes. 2019;12:713.

37. Zegeye A, Alebel A, Gebrie A, et al. Prevalence and determinants of antenatal depression among pregnant women in Ethiopia: a systematic review and meta-analysis. BMC Pregnancy Childbirth. 2018;18(462):1-12.

38. Ayano G, Tesfaw G, Shumet S. Prevalence and determinants of antenatal depression in Ethiopia: A systematic review and meta-analysis. PLoS One. 2014. 14(2):e0211764.

39. Fekadu Dadi A, Wolde HF, Baraki AG, Akalu TY. Epidemiology of antenatal depression in Africa: a systematic review and meta-analysis. BMC Pregnancy Childbirth. 2020;20(251):1-13.

40. Senturk V, Abas M, Berksun O, Stewart R. Social support and antenatal depression in extended and nuclear family environments in Turkey: a cross-sectional. BMC Psychiatry. 2011;11(48):1-10.

41. Yanikkerem E, Ay S, Mutlu S, Goker A. Antenatal depression: prevalence and risk factors in a hospital based Turkish sample. J Pak Med Assoc. 2013;63(4):472-477.

42. Cankorur VS, Abas M, Berksun O, Stewart R. Social support and the incidence and persistence of depression between antenatal and postnatal examinations in Turkey: a cohort study. BMJ Open. 2015;5: e006456. doi:10.1136/bmjopen-2014-006456

43. Phoosuwan N, Manasatchakun P, Eriksson L, Lundberg PC. Life situation and support during pregnancy among Thai expectant mothers with depressive symptoms and their partners: a qualitative study. BMC Pregnancy Childbirth. 2020;20(207):1-10.

44. Phoosuwan N, Manwong M, Lundberg PC. Perinatal depressive symptoms among Thai women: A hospital-based longitudinal study. Nurs Health Sci. 2020;22(2):309-317.
International Journal of Women's Health

\section{Publish your work in this journal}

The International Journal of Women's Health is an international, peerreviewed open-access journal publishing original research, reports, editorials, reviews and commentaries on all aspects of women's healthcare including gynecology, obstetrics, and breast cancer. The manuscript management system is completely online and includes a very quick and fair peer-review system, which is all easy to use. Visit http://www.dovepress.com/testimonials.php to read real quotes from published authors. 